


\title{
Occlusal variation among Sharkhan rural population
}

\author{
Nada M AL - SAYAGH*
}

\begin{abstract}
The purpose of this study was to provide information about the occlusal variations among Sharkhan rural population and explore significant sex and age differences in occlusion.

A sample of (194) subjects (117 male and 77 female) aged (12-50) year was examined. Many occlusal features were studied. The results indicate that most of the subjects had class I molar and canine occlusion, approximately $(3 / 4)$ of the sample had normal overjet and correct midline relation, about $(1 / 2)$ of the sample had normal overbite The most common malocclusion features was crowding in the lower anterior teeth and spacing in the upper anterior teeth followed by deep bite. While the crossbite and scissors bite were less likely to occur among the total sample.

It was found the females had a high percentage of class II canine relation, and missing posterior teeth, while the males had a high percentage of class III canine relation, deep bite and upper posterior teeth rotation.

With advancing age the prevalence of lower anterior crowding was decreased while the prevalence of missing posterior teeth were increased.
\end{abstract}

Key Words: Occlusal variation, malocclusion, sex difference in occlusion, age difference in occlusion.

\section{الخلاصة}

كان هدف هذه الدراسة أن تزود معلومات حول اختِلفات الإطباق بين ســـــان قريــة

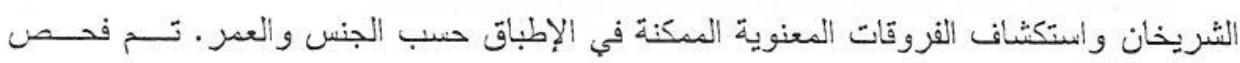

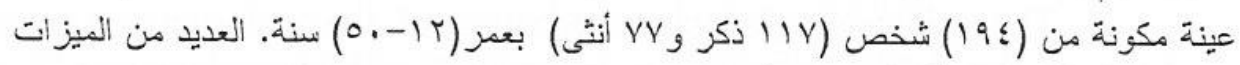

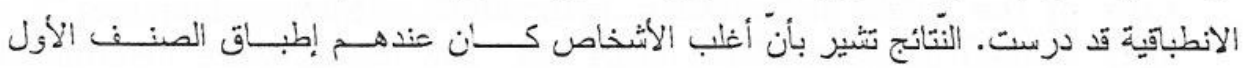

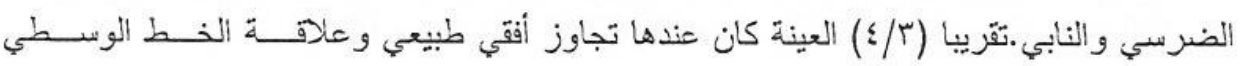
الصحيحة:

*Nada Mohammad AL-SAYAGH; BDS, MSc: Assistant Lecturer. Department of Pedodontics, Orthodontics, \& Preventive Dentistry, College of Dentistry, University of Mosul, Mosul, IRAQ. 


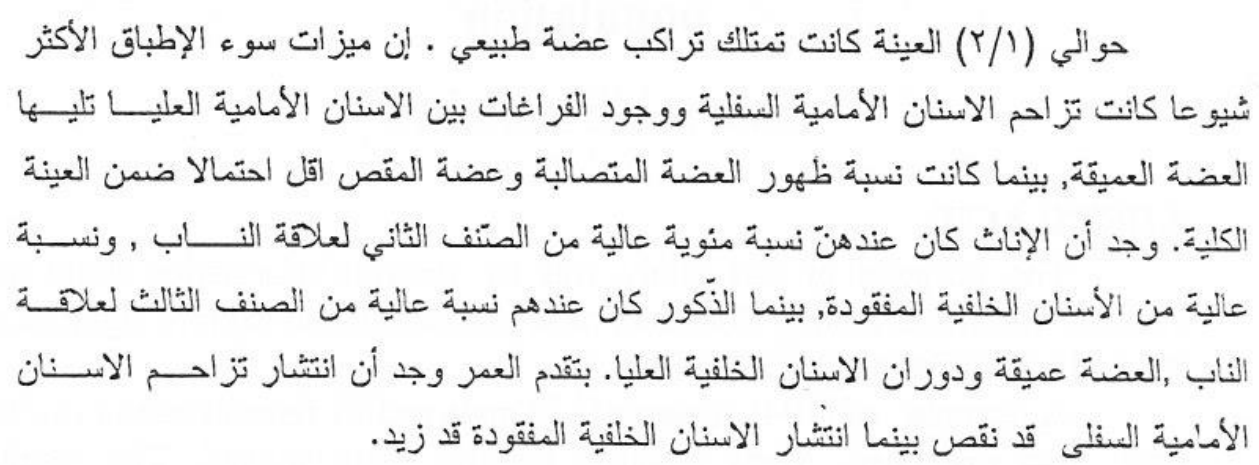

\section{INTRODUCTION}

The occlusion and position of the teeth are determined by a number of features, each having a continuous range of variation. Many studies have been conducted in different parts of the world in order to determine the variation in occlusion.

In the East Slovakian region, Frankovic et al. ${ }^{(1)}$ examined some of adolescent aged (15-18) years, the author recorded the following values to Angles classification: class II/1(14.3\%), class II/2(7.5\%), class III $(3.1 \%)$. Incidence of malocclusion: deep occlusion (23.8\%), labial occlusion (4.4 $\%$ ), open occlusion (5.8\%), and crossed occlusion (7.3\%).

The prevalence of cross bite in Mexican children aged (2-17) years were evaluated ${ }^{(2)}$, the results indicated that about $(36.6 \%)$ evidenced cross bite of each sex, in (69.6\%) the teeth were anterior, in (17.8\%) they were posterior, and in (15.5\%) their position was mixed.

The epidemiological characterization of the occlusion was made on basis of the Angle classification in the South of Metropolitan area (3), with ages ranged between (7-14) years old . The results were determined as follows: class I, (84.7\%); class II, (10.9\%); class III, (4.3\%).

The prevalence of the dentofacial anomalies in the age group (15-74) was described ${ }^{(4)}$. The main findings were; sever crowding in the mandible, an Angle class II situation and a maxillary overjet of greater than (5) $\mathrm{mm}$ were seen. 
The occlusion pattern among Tanzanian adults was described ${ }^{(5)}$. Most of the subjects had Angles class I molar occlusion. Transversal occlusal anomalies were rare. Spacing was more prevalent than crowding. Anterior openbite and spacing were the most prevalent condition in this study:

The occlusal status was assessed in Libyan children ${ }^{(6)}$. Angle class I was found to be the predominant type (94.5\%) over bite relationship in the majority $(50.6 \%)$ was within the incisal third. Mean overjet measurements ranged from (2) $\mathrm{mm}$ to (8) $\mathrm{mm}$. Small proportion (13.4) of the children had a sign of crowding.

The prevalence of malocclusion amongst young Chinese were assessed ${ }^{(7)}$, using the occlusal index. The most commonly occurring features was Crowding followed by class II malocclusion and class III malocclusion.

El-Mangoury and Mostafa ${ }^{(8)}$ explore the possible significant sex difference in occlusion, provide information about the occlusal variation among Egyptians adults. The results indicate that a significant sex difference in occlusion, Angle class I and Angle class II. Further, Angle class III type 1 (edge- to-edge) is more prevalent than either class III type 2 (normal anterior over bite) or type 3 (anterior cross bite).

An epidemiologic study was performed ${ }^{(9)}$, on suburban and rural Nigerian children aged (12) year old were examined .No significant differences were found between gender.

The prevalence of certain malocclusion traits in an Australian adult population aged (18-64) year was examined ${ }^{(10)}$. The prevalence of many malocclusion traits did not change; however, with advancing age, the incidence of posterior crowding, posterior rotation, posterior cross bite anterior irregularities increased significantly.

In Iraq, an oral health survey was conducted on senior secondary students ${ }^{(11)}$. The most frequently noted malocclusion involved the occurrence of over bite and overjet in the same individual. Crowding of teeth was second in frequently. A study of Kinaan ${ }^{(12)}$ was carried out on referred orthodontic cases. The proportions of variations in the antero-posterior arch relationship, overjet and over bite are greatly different from European values. However, there are no data available about the nature of occlusal features in Sharkhan rural area in Mosul City. 
The purpose of this study is three-dimensional: 1. Provide information about the occlusal variation among Sharkhan rural populations. This may be used as a basis for preventive as well as interceptive orthodontics. 2.Explore the possible significant relationships of the femalemale difference in occlusion, this may offer a reliable and valid research tool for investigating the etiology of malocclusion. 3. Investigate the occlusal variations according to the different age groups.

\section{MATERIALS AND METHODS}

The sample of this study was consisted of (194) subjects ( 77 female and 117 male) selected from Sharkhan rural population, all the subjects had the following criteria: age range was (12-50) years. No previous history of orthodontic treatment. No serious diseases which could affect craniofacial growth and development. No history of skull fractures and no facial operations.

The following materials were used: dental mirrors, dental probes, calibration vernier, kidney dishes, pans for sterilization, cotton and sterilization solution.

All clinical examinations were made by the same examiner in school while the subjects seated on dental chair, and the following occlusal features were assessed according to the criterion defined below.

Each dental arch is divided into three segments: an anterior segment and two posteriors segments (left and right), each segment is considered in term of intra-arch alignment and inter-arch relationship.

\section{Inter-Arch Relationship:}

The inter-arch relationship was recorded in centric occlusion in three planes of spaces.

\section{Sagittal Occlusion:}

The sagittal occlusion was defined at the first molar according to Angle ${ }^{(13)}$, and at the canine according to Foster and Walpole Day ${ }^{(14)}$.

\section{Incisal Overjet:}

Is the horizontal distance between the labial surfaces of upper and lower central incisors, and it was measured according to Kinaan (15).

1. Normal overjets: positives overjet of (1-4) mm. 
2. Increased overjet: positives overjet of (5) $\mathrm{mm}$ or more.

3. Edge-to-Edge (zero) overjet: Upper and lower incisors edge-to-edge in occlusion.

4. Reduced (reversed) overjet More than two incisors in reversed overjet.

5. Instanding : one or two upper incisorrs in reversed overjet

N.B. the category "instanding "was always used in combination with one of the other categories (Foster and Walpole Day) ${ }^{(14)}$.

\section{Incisal Overbite:}

Is the vertical distance between the incisal edges of the upper and lower central incisors, and measured according to Kinaan ${ }^{(12)}$.

1. Normal overbite, a positive overbite of (1-4) $\mathrm{mm}$.

2. Increased

3. Overbite, a (5) mm or over.

4. Decreased overbite, a (zero) $\mathrm{mm}$ or openbite.

\section{Cross-bite:}

Recorded according to Kinaan ${ }^{(15)}$ for each side when one or more of the upper premolars or molars deviate bucco-lingually greater than half of cusp, so that the cusps had passed one another, it may be unilateral or bilateral.

\section{Scissors-bite:}

Complete bucco version of maxillary posterior teeth, and it recorded according to Kerosuo et al. ${ }^{(16)}$. On each side when the lingual cusp of one or more premolars or molars occludes buccally to the buccal cusp of the corresponding lower teeth.

\section{Midline Relation:}

Is defined according to Summer ${ }^{(17)}$, as the distance, in millimeters, between the mid point of the two maxillary central incisors and the mid point of the two mandibular central incisors in the horizontal plane.

\section{Intra-Arch Features:}

\section{Dental Arch Crowding:}

Overlapping of teeth in the existing dental arch, or insufficient space for unerupted teeth to erupt into the arch with overlapping. These are assessed anteriorly and posteriorly according to Bjork ${ }^{(18)}$. 


\section{Dental Arch Spacing:}

It refers to tooth separtion that exposes to view the interdental papillae on the alveolar crest. These are assessed anteriorly and posteriorly according to Bjork ${ }^{(18)}$ and Salzman ${ }^{(19)}$.

\section{Displaced Tooth:}

It was recorded according to Van Kirk \& Pennel ${ }^{(20)}$ when both contact points of the tooth are removed in the same direction from their position in ideal alignment.

\section{Rotated Tooth:}

Is present when the angle formed by the line projected through the contact areas of observed tooth and the ideal arch line is more than (30) degrees $^{(12)}$.

\section{Missing Teeth:}

Are assessed by actual count. Notation on missing teeth due to extraction, hypodontia, trauma, and impaction were taken.

\section{Statistical Analysis:}

Descriptive statistics including frequency tables and percentages were calculated for all occlusal features in response to the sex and age variables. The Chi square test was employed to show any statistically significant for each occlusal feature between the sexes and among different age groups. Probability levels of more than (0.05) were regarded as statistically insignificant, where as values less or equal to $(0.05)$ were considered as significant.

\section{RESULTS}

The percentage distributions of the inter-arch and intra-arch features were presented in tables (1) and (2) respectively for the total sample with the comparison between the males and females. While the percentage distribution of the inter-arch and intra-arch features according to the three age groups were illustrated in tables (3) and (4) respectively. 
Table (1): Percentage distribution of the inter-arch features for the total sample with the comparison between males and females

\begin{tabular}{|c|c|c|c|c|c|}
\hline & 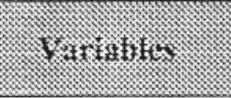 & 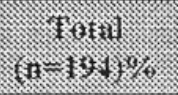 & 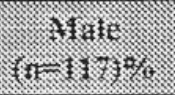 & (I) & $\mathrm{Stg}^{4}$ \\
\hline & \multicolumn{5}{|c|}{ 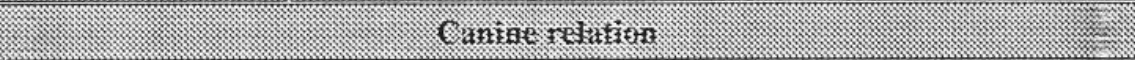 } \\
\hline \multirow{3}{*}{ s. } & Class I & 77.48 & 80.22 & 74.57 & N.S \\
\hline & Class II & 15.53 & 9.89 & 23.72 & $S$ \\
\hline & Class III & 6.62 & 9.89 & 1.69 & $S$ \\
\hline \multirow{3}{*}{ s. } & Class I & 77.86 & 79.75 & 75.41 & N.S \\
\hline & Class II & 17.14 & 12.65 & 22.95 & N.S \\
\hline & Class III & 5.00 & 7.59 & 1.64 & N.S \\
\hline \multicolumn{6}{|c|}{ (1) } \\
\hline \multirow{6}{*}{, } & Class I & 86.78 & 85.71 & 89.19 & N.S \\
\hline & Class II & 7.44 & 7.14 & 8.11 & N.S \\
\hline & Class III & 5.79 & 7.14 & 2.70 & N.S \\
\hline & Class I & 82.90 & 81.70 & 85.71 & N.S \\
\hline & Class II & 8.55 & 7.32 & 11.43 & N.S \\
\hline & Class III & 8.55 & 10.98 & 2.86 & N.S \\
\hline \multicolumn{6}{|c|}{ 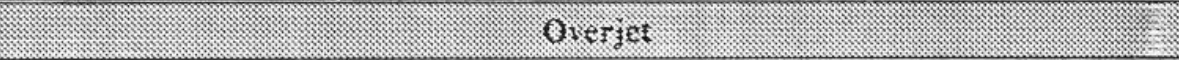 } \\
\hline & Normal & 74.64 & $73 .+2$ & 76.27 & N.S \\
\hline & Zero & 15.22 & 16.45 & 13.56 & N.S \\
\hline & Increase & 8.69 & 7.59 & 10.17 & N.S \\
\hline & Reverse & 1.45 & 2.53 & 0 & N.S \\
\hline & Instanding & 8.22 & 7.36 & 8.33 & N.S \\
\hline \multicolumn{6}{|c|}{ 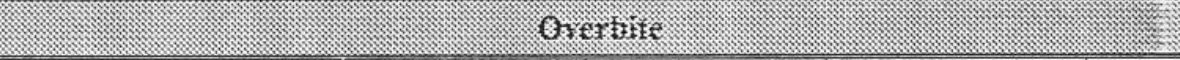 } \\
\hline & Normal & 52.17 & 46.34 & 60.71 & N.S \\
\hline & Zero & 14.49 & 12.20 & 17.85 & N.S \\
\hline & Deepbite & 32.61 & 40.24 & 21.43 & $\mathrm{~S}$ \\
\hline & Openbite & 0.72 & 1.22 & 0 & N.S \\
\hline \multicolumn{6}{|c|}{ 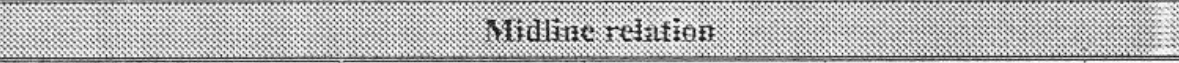 } \\
\hline & Deviate to right & 17.99 & 20 & 12.25 & N.S \\
\hline & Correct & 68.35 & 62.5 & 76.27 & N.S \\
\hline & Deviate to left & 13.67 & 17.5 & 8.47 & N.S \\
\hline \multicolumn{6}{|c|}{ ( rross bite } \\
\hline & Unilateral & 1.98 & 2.19 & 1.66 & N.S \\
\hline & Bilateral & 3.31 & +.39 & 1.66 & N.S \\
\hline \multicolumn{6}{|c|}{ 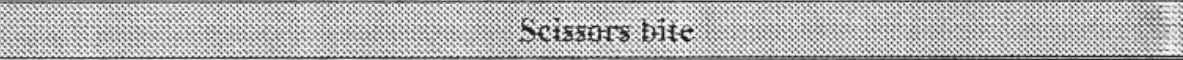 } \\
\hline & Unilateral & 1.32 & 1.11 & 1.6 & N.S \\
\hline & Bilateral & 0 & 0 & 0 & N.S \\
\hline
\end{tabular}

*N.S = not significant $; \mathrm{S}=$ Significant at $p<0.05$ 
Table (2): Percentage distribution of the intra-arch features for the total sample with the comparison between males and females

\begin{tabular}{|c|c|c|c|c|}
\hline 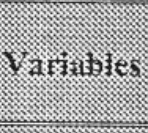 & 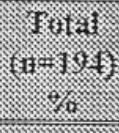 & 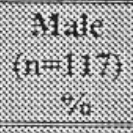 & 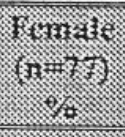 & 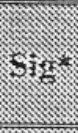 \\
\hline \multicolumn{5}{|c|}{ 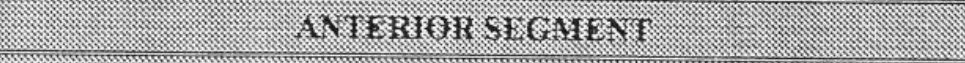 } \\
\hline \multicolumn{5}{|c|}{ Crutritirt: } \\
\hline Upper & 13.25 & 15.38 & 10 & N.S \\
\hline Lower & 33.77 & 34.07 & 33.33 & N.S \\
\hline \multicolumn{5}{|c|}{ fy,zening: } \\
\hline Upper & 25.16 & 26.37 & 23.33 & N.S \\
\hline Lower & 9.27 & 9.89 & 8.33 & N.S \\
\hline \multicolumn{5}{|c|}{ 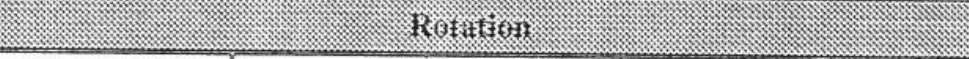 } \\
\hline Upper & 0.66 & 0.73 & 0.55 & N.S \\
\hline Lower & 0.44 & 0.55 & 0.28 & N.S \\
\hline \multicolumn{5}{|c|}{ 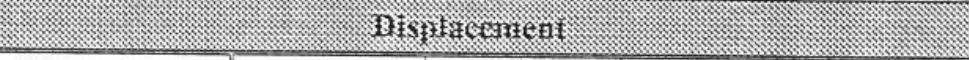 } \\
\hline Upper & 1.10 & 1.46 & 0.55 & N.S \\
\hline Lower & 0 & 0 & 0 & N.S \\
\hline \multicolumn{5}{|c|}{ Traviaraz } \\
\hline Upper & 1.21 & 1.11 & 1.38 & N.S \\
\hline Lower & 0.33 & 0.18 & 0.55 & N.S \\
\hline \multicolumn{5}{|c|}{ 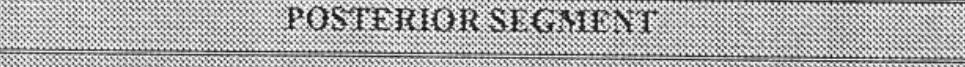 } \\
\hline \multicolumn{5}{|c|}{ Crotrititz: } \\
\hline Upper & 0.66 & 1.09 & 0 & N.S \\
\hline Lower & 0 & 0 & 0 & N.S \\
\hline \multicolumn{5}{|c|}{ 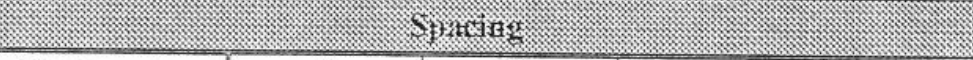 } \\
\hline Upper & 0 & 0 & 0 & N.S \\
\hline Lower & 4.46 & 3.29 & 6.66 & N.S \\
\hline \multicolumn{5}{|c|}{ 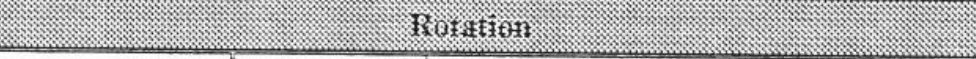 } \\
\hline Upper & 3.89 & 5.08 & 2.08 & $S$ \\
\hline Lower & 4.47 & 4.67 & 4.16 & N.S \\
\hline \multicolumn{5}{|c|}{ 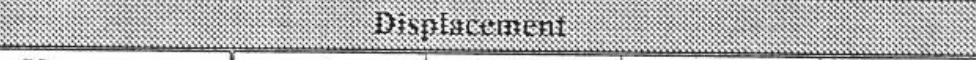 } \\
\hline Upper & 0 & 0 & 0 & N.S \\
\hline Lower & 0.22 & 0.27 & 0 & N.S \\
\hline \multicolumn{5}{|c|}{ 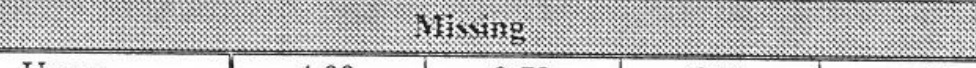 } \\
\hline Upper & 4.99 & 3.73 & 6.94 & $\mathrm{~S}$ \\
\hline Lower & 6.30 & 4.25 & 9.75 & $S$ \\
\hline
\end{tabular}

*N.S=not significant $; \mathrm{S}=$ Significant at $p<0.05$ 
Table (3): Percentage distribution of the inter-arch features for the three age group

\begin{tabular}{|c|c|c|c|c|}
\hline Y & (12) & (for & (⿻一力口) & Sin \\
\hline \multicolumn{5}{|c|}{ 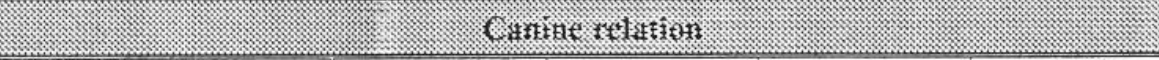 } \\
\hline Class I & 73.33 & 88.24 & 75 & $S(a b)$ \\
\hline Class II & 20 & 9.43 & 22.5 & N.S \\
\hline Class III & 6.66 & 1.89 & 2.5 & N.S \\
\hline Class I & 70.83 & 88.24 & 70.73 & $\mathrm{~S}(\mathrm{ab} \cdot \mathrm{bc})$ \\
\hline Class II & 18.75 & 11.76 & 26.83 & N.S \\
\hline Class III & 10.41 & 0 & 2.44 & N.S \\
\hline \multicolumn{5}{|c|}{ 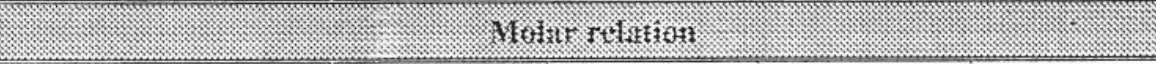 } \\
\hline Class I & 86.27 & 91.49 & 92.31 & N.S \\
\hline Class II & 7.84 & 0 & 3.85 & $S(a b)$ \\
\hline Class III & 5.88 & 8.51 & 3.85 & N.S \\
\hline Class I & 88.24 & 91.11 & 91.30 & N.S \\
\hline Class II & 7.84 & 2.22 & 4.35 & N.S \\
\hline Class III & 8.92 & 6.66 & +.35 & N.S \\
\hline \multicolumn{5}{|c|}{ 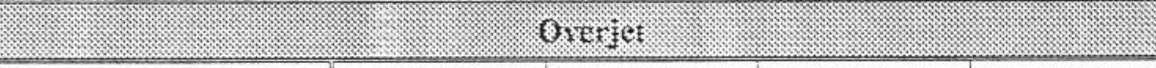 } \\
\hline Normal & 73.85 & 81.48 & 80.95 & N.S \\
\hline Zero & 11.32 & 5.55 & 11.90 & N.S \\
\hline Increase & 13.21 & 3.70 & 0 & N.S \\
\hline Decrease & 1.89 & 9.26 & 7.14 & N.S \\
\hline Instanding & 7.54 & 1.34 & 7.14 & N.S \\
\hline \multicolumn{5}{|c|}{ 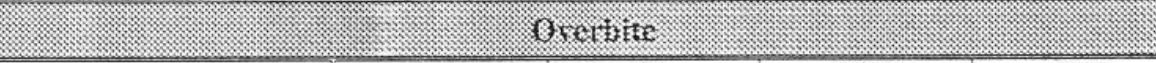 } \\
\hline Normal & 58.18 & 50 & 69.05 & N.S \\
\hline Zero & 12.73 & 40.74 & 23.18 & N.S \\
\hline Deepbite & 29.09 & 1.85 & 0 & N.S \\
\hline Openbite & 0 & 7.40 & 7.14 & N.S \\
\hline \multicolumn{5}{|c|}{ 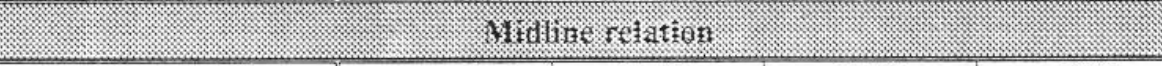 } \\
\hline Deviate to right & 13.20 & 7.55 & 23.81 & N.S \\
\hline Correct & 67.92 & 73.58 & 73.81 & N.S \\
\hline Deviate to left & 18.87 & 18.87 & 2.38 & $\mathrm{~S}(\mathrm{ac} \cdot \mathrm{bc})$ \\
\hline \multicolumn{5}{|c|}{ 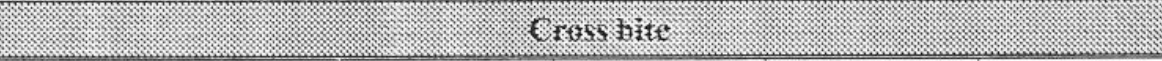 } \\
\hline Unilateral & 3.7 & 3.5 & 2.23 & N.S \\
\hline Bilateral & 0 & 1.78 & 0 & N.S \\
\hline \multicolumn{5}{|c|}{ 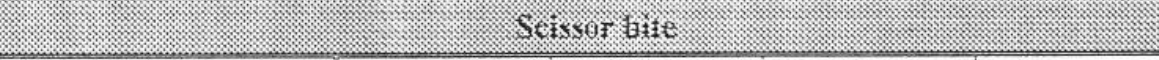 } \\
\hline Unilateral & 1.9 & 0 & 0 & N.S \\
\hline Bilateral & 0 & 0 & 0 & N.S \\
\hline
\end{tabular}

$*$ N.S=not significant $; \mathrm{S}=$ Significant at $p<0.05$ 
Table (4): Percentage distribution of the intra-arch features according to the three age groups

\begin{tabular}{|c|c|c|c|c|}
\hline (x) & (2+1) & 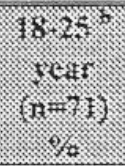 & 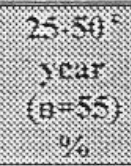 & Stzo \\
\hline \multicolumn{5}{|c|}{ 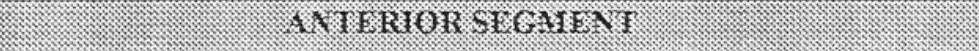 } \\
\hline \multicolumn{5}{|c|}{ 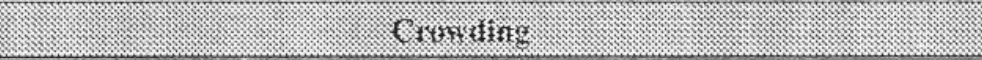 } \\
\hline Upper & 13.21 & 16.07 & 6.98 & N.S \\
\hline Lower & 35.85 & 44.64 & 16.28 & $\mathrm{~S}(\mathrm{~b} . \mathrm{c})$ \\
\hline \multicolumn{5}{|c|}{ (f), stcinits } \\
\hline Upper & 28.30 & 25 & 27.91 & N.S \\
\hline Lower & 7.55 & 10.71 & .23 .26 & $\mathrm{~S}(\mathrm{a} . \mathrm{c})$ \\
\hline \multicolumn{5}{|c|}{ 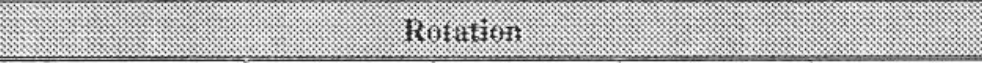 } \\
\hline Upper & 0.94 & 0.30 & 0.39 & N.S \\
\hline Lower & 0.63 & 0 & 0.39 & N.S \\
\hline \multicolumn{5}{|c|}{ 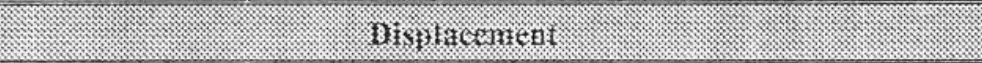 } \\
\hline Upper & 2.52 & 0.30 & 0 & $S(a . c)$ \\
\hline Lower & 0 & 0 & 0 & N.S \\
\hline \multicolumn{5}{|c|}{ 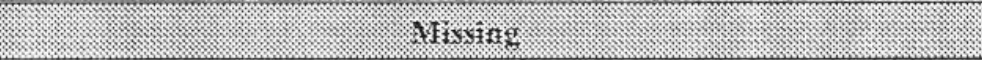 } \\
\hline Upper & 0.63 & 2.08 & 0.39 & N.S \\
\hline Lower & 0 & 0.30 & 0.39 & N.S \\
\hline \multicolumn{5}{|c|}{ 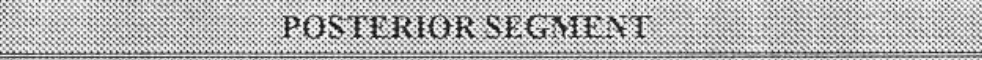 } \\
\hline \multicolumn{5}{|c|}{ ( } \\
\hline Upper & 3.77 & 0 & 0 & N.S \\
\hline Lower & 0 & 1.79 & 0 & N.S \\
\hline \multicolumn{5}{|c|}{ S. } \\
\hline Upper & 3.77 & 0 & 2.33 & N.S \\
\hline Lower & 0 & 3.57 & 2.33 & N.S \\
\hline \multicolumn{5}{|c|}{ 6 604 - } \\
\hline Upper & 4.30 & 4.02 & 2.62 & N.S \\
\hline Lower & 4.07 & 4.69 & 4.36 & N.S \\
\hline \multicolumn{5}{|c|}{ (3) } \\
\hline Upper & 0 & 0 & 0 & N.S \\
\hline Lower & 0.24 & 0 & 0.29 & N.S \\
\hline \multicolumn{5}{|c|}{ 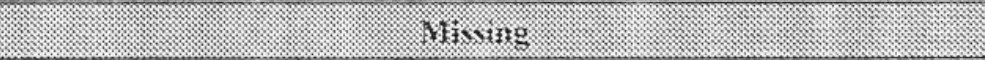 } \\
\hline Upper & 0.70 & 3.61 & 10.98 & $S(a, b, c)$ \\
\hline Lower & 0.47 & 6.02 & 13.60 & S(a.b.c) \\
\hline
\end{tabular}

* N.S = not significant $; S=$ Significant at $p<0.05$ 


\section{DICUSSION}

\section{Distribution of the Occlusal Features in the Total Sample Sagittal Relationship:}

Class I sagittal molar and canine relationship for both sides were more prevalent among this rural population then followed by Class II and then Class III.This is in agreement with the finding of Frankovic et al. ${ }^{(1)}$, Sanchez-perz et al. ${ }^{(3)}$, Ommar ${ }^{(6)}$, Mugonzibwa ${ }^{(21)}$, Kinann ${ }^{(15)}$, but disagreement with the finding of Foster\&Walpole Day ${ }^{(14)}$ who found the most common arch relationship is Class III.

\section{Incisal Overjet:}

A large proportion of the subjects had a normal overjet and about (1/6) of the sample had an edge-to-edge occlusion while the reversed overjet was uncommon. This, of course, reflects the findings of the dental arch relationship. There is only a slight higher tendency toword increased overjet than toward its reduction, this is in accordance with Kinnan ${ }^{(15)}$ while in the United Kingdom it is much higher ${ }^{(15)}$.

\section{Incisal Overbite:}

Almost half of the subjects had normal incisal overbite again reflecting the high proportion with class I dental arch relationship. Less than half of the subjects had an increased overbite, while the openbite was rare. This is inaccordance with Ommar ${ }^{(6)}$ and Foster\&Walpole Day ${ }^{(14)}$, while Kinaan ${ }^{(15)}$ found a higher value of openbite.

A correct midline relationship tends to be more common, while the deviation of the midline to the right and left side was nearly the same.

Transveral occlusal anomalies including crossbite and siscerbite were rare, this is in accordance with Mugonzibwa ${ }^{(5)}$.

\section{Intra-arch Deviations:}

The most commonly malocclusion features was crowding, this is in agreement with the Kinaan ${ }^{(15)}$, Al-Alousi ${ }^{(11)}$, Nganga ${ }^{(22)}$, Burgersdij ${ }^{(4)}$ and Makoni et al. ${ }^{(23)}$. Crowding of the incisors was almost twice as prevalent in the lower arch as in the uppers. In contrast, spacing was much more prevalent in the upper arch, this is in agreement with Kinaan ${ }^{(21)}$.

The teeth most frequently missing were the lower posterior particulary the first molar, then followed by the upper posterior. The anterior teeth especially the lower being the least frequently lost. This is in agreement with Massler \& Frankel ${ }^{(24)}$. 


\section{Occlusal Variation According to Sex:}

It must be emphasized that the general pattern of occlusal variation for males does not differ from the females. However there is a significant difference numerically for some occlusal features.

It was found that the males had a higher prevalence of class III canine relation than the females, this is in disagreement with the work of Goose et al. ${ }^{(25)}$, Grewe et al. ${ }^{(26)}$, Helm ${ }^{(27)}$ and Solow ${ }^{(28)}$ who reported similar incidence of class III for both sexes. While the females had a higher prevalence of class II canine relation than the males.

Deepbite is about two times higher in males than females, these seem to reflect the differences found in certain craniofacial and dentoalveolar structures, including greater mandibular plane inclination among females and a tendency to anterior rotation in males.

Posterior missing teeth in the upper and lower arch was about two times higher in females than in males.

\section{Occlusal Variation According to Age:}

In general, there was a little difference for occlusal features among the three age groups. A significant age difference in sagittal occlusion exist for class I canine relation which was more prevalent in the young age group than other groups and class II molar relation which was more prevalent in the adolescent group.

Concerning the vertical relationship, the adolescent tend to have more deepbite prevalence than other groups, while with aging the subjects tend to have more openbite, this may attributed to increased the growth of posterior dentoalveolar height.

The older age group tend to have a less prevalence of the midline to drift to the left side and a more prevalent to drift to the right side, this may attributed to the missing of right posterior teeth.

With aging, lower anterior teeth crowding was decreased significantly, while lower anterior teeth spacing was increased, this also may attributed to the missing of posterior teeth, this in accordance with Lombardi \& Bailit ${ }^{(1)}$, Smith et al. ${ }^{(31)}$ and Corruccini ${ }^{(29)}$.who mentioned that age progression increases occlusal variation, as mesial drift increases crowding while any reduction in crowding engendered by tooth loss would be overcompensated by abnormal contacts resulting from drift and spacing.

\section{CONCLUSION}

$*$ Most of Sharkhan population had class I molar and canine occlusion, approximatly $(3 / 4)$ of the sample had normal overjet and correct midline 
relation, about $(1 / 2)$ of the sample had normal overbite The most common malocclusion features was crowding in the lower arch followed by deep bite and spacing in the upper arch, while the crossbite and scissors bite were less likely to occur among the total sample.

\% Comparison between the two sexes indicated that the females had a high percentage of class II canine relation, missing upper and lower posterior teeth, while the males had a high percentage of class III canine relation, deep bite and upper posterior teeth rotation.

* The prevalence of many occlusal features did not change with age, however, with advancing age the prevalence of lower anterior crowding was decreased while the prevalence of lower anterior spacing and posterior missing teeth particularly in the lower arch were increased.

\section{REFERENCES}

1. Frankovic K, Kucharska D, Takac L. Incidence of maxillary orthopedic anomalies in adolescents. Prakt Zuhn Lek. 1990; 38(8): 250-254.

2. Ojeda LS, Teja DeLa, Angle E. Prevalence of cross-bite in Mexican children. Pract Odontol. 1990; 11(10): 11-15.

3. Sanchez Perez TL, Saenz LP, Alfaro P. Occlusion distribution in a 7-to-14 year old student population. Rev ADM. 1991; 48(1): 52-55.

4. Burgersdijk R, Truin GJ, Frankenmolen F, Kalsbeck $H$ van't Hof M, Mulder J. Malocclusion and orthodontic treatment need of 15-74 year old Dutch aduls. Community Den Oral Epidemiol. 1991; 19(2): 64-67.

5. Mugonzibwa EA. Occlusal survey in a group of Tanzanian adults. Afr Dent J. 1993; 7: 6-10.

6. Ommar SM. Occlusal status and permenant teeth eruption in Libyan children. J Indian Soc Prev Dent. 1994; 12(1): 1-6.

7. Tang EL. The prevalence of malocclusion amongst Hong Kong male dental students. Br J Orthod. 1994; 21(1): 57-63.

8.El-Mangoury NH, Mostafa YA. Epidemiologic panorama of dental occlusion. Angle Orthod. 1990; 60(3): 207-213.

9. Otuyemi OD, Abidoye RO. Malocclusion in 12-year-old suburban and rural Nigerian children. Community Dent Health. 1993; 10: 375-380.

10. Tod MA, Travrne AA. Prevalence of malocclusion traits in Australian adult population. Aust Orthod J. 1997; 15(1): 16-22.

11. Al-Alousi W, Jamison HH, Legler DD. A survey of oral health in Iraq population characteristics, occlusion and enamel mottling of senior secondary school students. Iraqi Dent J. 1982; 9:8-16.

12. Kinaan BK. The problem of malocclusion in Iraq. Iraqi Dent J. 1982; 9: 24-28. 
13. Angle EH. Classification of malocclusion. Dent Cosmos. 1988; 41: 248264.

14. Foster TD, Day AJW. A survey of malocclusion and the need for orthodontic treatment in a Shropshire school population. $\mathrm{Br}$ JOrthod. 1973; 1: 73-78.

15. Kinaan BK, Burke PH. Quantitative assessment of the occlusal features. Br J Orthod. 1981; 8: 149-156

16. Kerosuo H, Lain T, Nyyssonen V, Honkala E. Occlusal characteristics ingroups of Tanzanian and Finnish urban schoolchildren. Angle Orthod. 1991; 61(1): 49-56.

17. Summer CJ. A system for identifying and scoring occlusal disorders. Am J Orthod. 1971; 59: 552-567.

18. Bjork A, Krebs A, Solow B. A method for epidemiological registration of malocclusion. Acta Odontol Scand. 1964; 22: 27-41.

19. Salzmann JA. Handicapping malocclusion assessment to establish treatment priority. Am J Orthod. 1968; 54 (10): 749-769.

20. VanKirk JE, Pennel EII. Assessment of malocclusion in population groups. Am J Orthod. 1959; 45(10): 752-767.

21. Kinaan BK. A quantitative assessment of the occlusal features and a simple orthodontic treatment need index. MMedSc thesis submitted to the University of Sheffield. England. 1978.

22. Ng'ang'a PM. A study of occlusal anomalies and tooth loss in children aged 13-15 years in Nairobi. East Afr Med J. 1997; 52(7): 491-494.

23. Makoni F, Frenckel JE, Sithole WD. Oral health status among secondary school students in Harare, Zimbabwe. J Dent Assoc S Afr. 1997; 52(7): 491-494.

24. Massler M, Frankel JM. Prevalence of malocclusion in children aged 14 to 18 years. Am J Orthod. 1951; 37: 751-768.

25. Goose D H, Thomson D G, and Winter FC. Malocclusion in school children of the west Midlands. Br Dent J. 1957; 102: 174-178.

26. Grew J M, Cervenka J, Shapiro B L, Witkop C J. Prevalence of malocclusion in Chippewa Indian children. J Dent Res. 1968; 47: 302-305.

27. Helm S. Malocclusion in Danish children with adolescent dentition: an epidemiologic study. Am J Orthod. 1968; 54: 352-368.

28. Solow B, Helm S. A method for tabulation and statistical evaluation of epidemiologic malocclusion data. Acta Odont Scand. 1968; 26: 63-88.

29. Corruccini RS, Whitly LD. Occlusal variation in a rural Kentucky community. Am J Orthod. 1981; 79:250-262.

30. Lombardi AV, Bailit HL. Malocclusion in the Kwaio, a Melanesian group on Malaita, Soloman Island. Am J Phys Anthropol. 1972; 36: 282-294.

31. Smith RJ Bailit, HL. Variation in dental occlusion and arches among Melanesians of Bougainville Island. Papua New Guinea. Am J Phy's Anthrop. 1977; 47: 195-208. 